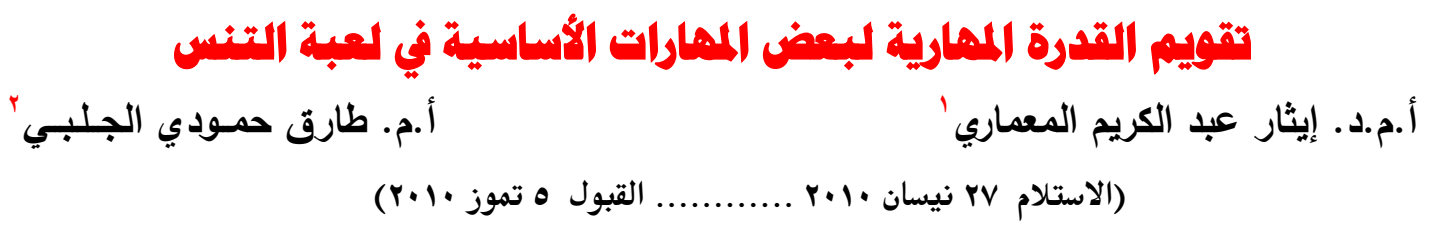

\begin{abstract}
unill
هدف البحث تقويم القدرة المهارية في لعبة التنس لطلاب السنة الدراسية الثانية لكلية التربية الرياضية ووضـع المستويات المعيارية لمهارات الضربة الأمامية والخلفية والإرسال وقد استخدم الباحثان المنهج الوصفي بأسلوب المستح وضسمت عينـة البحـث (179) طالباً وهم يمثلون (ع •,و\٪) طالباً من مجمتع البحث ، وتم استخدام اختبار هوايت للتحصيل لقياس مهارتي الضربة الأرضية الأماميـة والخلفية واختبار كوبان للإرسال وبعد إجراء الاختبارات ومعالجة البيانات إحصائيا تم التوصل إلى الاستنتاجات الآتية:

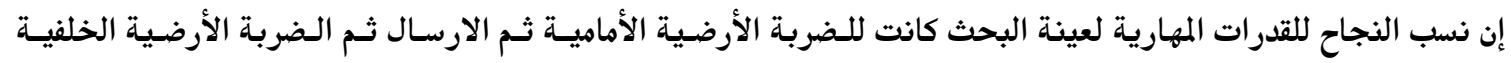
وحصول عينة البحث على نسب نجاح وبمستويات مختلفة للمهارات كذلك تم التوصل إلى جداول المستويات المعياريسة للقـدرات المهاريـة قيد الدراسة وبناءً على الاستنتاجات أوصى الباحثان بالاعتماد على الاختبـارات الموضسوعية والتقويم بـشكل مستمر في الكشف والتقدير لمستوى القدرة المهارية لعينة البحث لأهميتها في التعرف على مستوى الفرد ولزيادة فاعلية التعلم والتحضير للتطور.
\end{abstract}

\title{
Evaluating skill ability for some basic skills in tennis
}

\section{ABSTRACT}

This paper aims at ecaluating skill ability in tennis for the sopho more in the college of physical education and setting standards level for skills of forehand drive, backhand one and service.Both researchers utilized the descriptive approach and adapting the survey style. The sample consists of $(166)$ students represented $(\% 97,4)$ students of the total. Also Hewit test for measuring skills of forehand and backhand drive and Coban test for service are utilized, after carrying out the tests and processing data statiscally, the following conclusions have been reached.The success rates for skill abilities for research sample pertain to forhand drive, service and backand drive.The sample gained success rates for different levels of skills. Furthermore, the tables for the standards levels of skills abilities under study were reached mumbers of recommendations were proposed by both researchers. 
تتميز الدراسة العلمية الموضوعية للسلوك باعتمادها اعتماداً أساسيا على الأساليب الكمية في قياس هذا السلوك لمختلف جوانبه فبدون هذه الأساليب تقتصر دراسة السلوك على الوصف اللفظي والملاحظة الذاتية والتأملات الفردية.

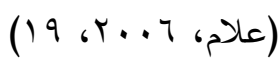

وتعد الاختبارات والمقاييس احد وسائل التقويم والتثخيص والتوجيه وهي احد أثكال الأسلوب العلمي المبني على

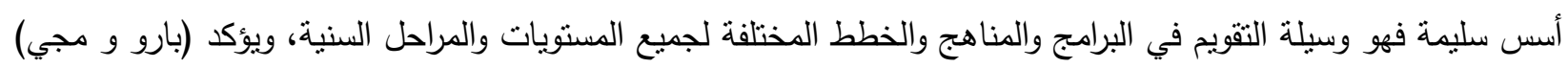

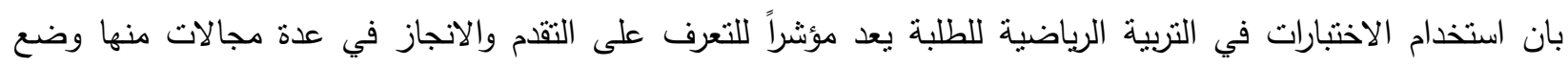
الدرجات، التقييم، التوجيه، الدافعية، البحث، فضلاً عن مساهمة القياس والاختبار في تقويم واختبار البرنامج والطرائق

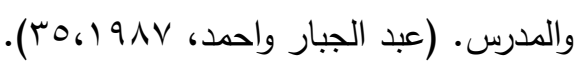
ولقد لاقت لعبة التسس الاهتمام الكبير في دول العالم إذ نلاحظ منافسة الدول على إقامة بطولات التتس وقد شمل هذا

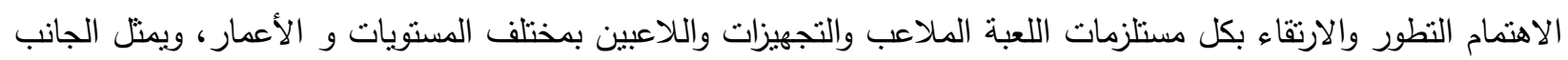

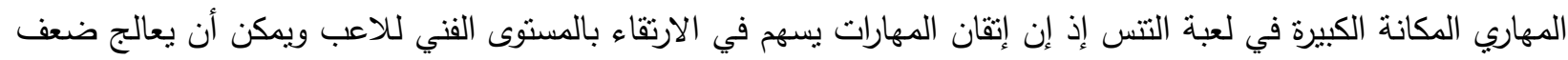

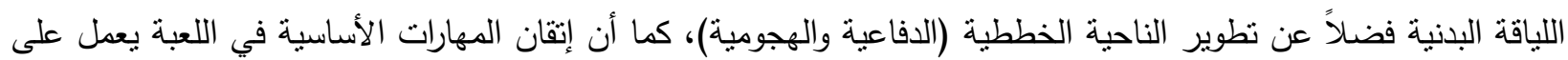
امتلاك الحالة النفسية الجيدة والتقة في المباراة. إن أهمية البحث تتجلى في نتاول القدرة المهارية في لعبة النتس وتقويمه لاى طلاب التربية الرياضية لههارات

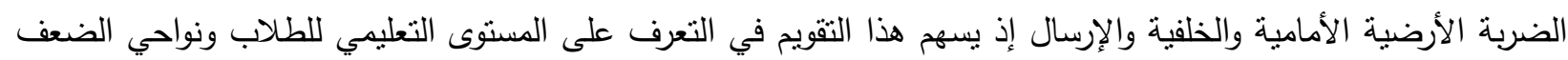
والقوة لديهم ولقد لجأ الباحثان إلى استخدام اختبارات مقننة تسهم في زيادة دافعية وفاعلية الأداء لاى الطلاب وهذا التقويم لاثك أيضا يسهم في الارتقاء بالأداء الفني للعبة.

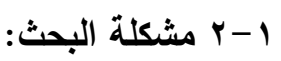
إن معرفة المستويات المهارية لدى المتعلمين نساعد الباحثين والمدربين في تحديد مستوى التطور التعليمي والتدريبي للاعبين، ومن خلال الاختبارات الموضوعية يستطيع المدرب أو المدرس أن يحصل على مستويات قدراتهم المهارية والتي

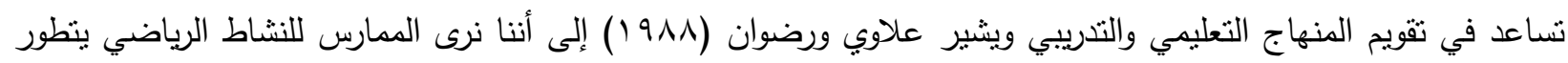
في النمو البدني والحركي والمهاري، كما أن دوافعه واتجاهاته وميولهُ تتغير و تتعدل كما أنه يكتسب العديد التهيد من السمات والقدرات لذا فإن الحكم على كل حصائل العملية التربوية الرياضية من الناحيتين الكمية والنوعية هي الجوهر الحقيقي لعملية

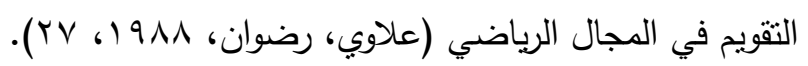
إن مشكلة البحث تكمن في التعرف على القدرة المهارية للمهارات الأساسية(الضربة الأرضية الأمامية والخلفية وضربة

الارسال ) من ثم تقويمها.

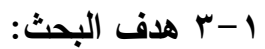

1-r-1 تقويم القدرة المهارية في لعبة التس لطلاب السنة الدراسية الثانية لكلية التربية الرياضية لمهارات الضربة الأمامية والخلفية وضربة الإرسال.

1-r-r وضع مستويات معيارية للمهارات الأساسية في لعبة التنس لطلاب السنة الدراسية الثانية لكلية التربية الرياضية.

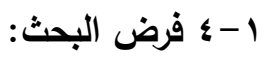

1-ـ - انتباين مستويات أداء بعض المهارات الأساسية في لعبة التتس لدى طلاب السنة الدراسية الثانية كلية التربية الرياضية. 


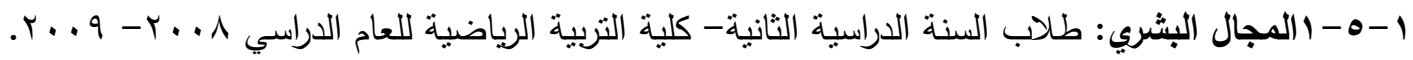

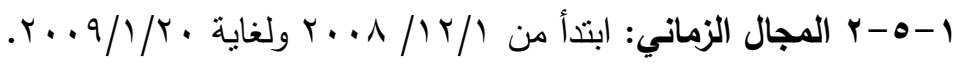
1- - ب- المجال المكاني: ملاعب التنس في كلية التربية الرياضية.

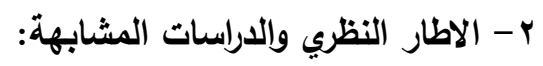

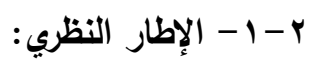
rيرى (جابر) بأن التقويم عبارة عن "التوصل إلى اتخاذ قرارات خاصة بدقة البيانات وجودتها وصلاحيتها أما (روث ابرناني) فيرى أن التقويم عبارة عن عملية تربوية يستخدم فيها طرق القياس وصولاً بالمعطيات بنتائج موضوعية متقدمة والتي تتتج عن مقارنات بأفكار وتصور جديدين. وترى مارجريت أن التقويم عبارة عن "عملية من شأنها إصدار أحكام حول نتائج قياسات واختبارات موضوعية وذللك بالاستتاد على معايير معينة" ويتفق كل من (كركندال وكاربر وجونسون) في تعريفهم للتقويم

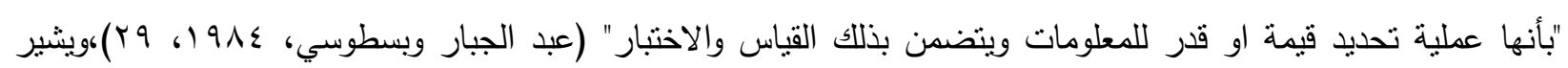
(بومجارتز) إلى أن التقويم هو العملية التي تنتخدم المقاييس وغرض المقاييس جمع البيانات وفي عملية التقويم تفسر هذه

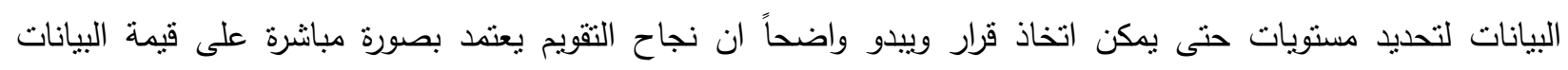

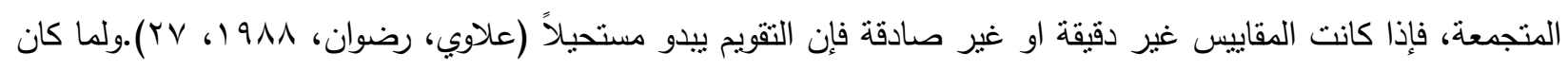

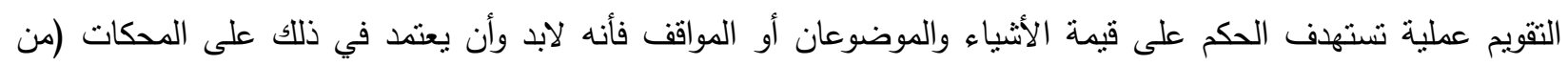

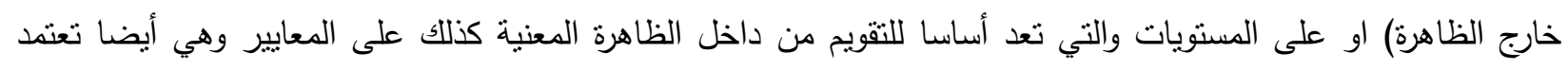
على التقويم من داخل الظاهرة وهي في شكل جداول تتضمن الدرجات الخام ويقابلها الدرجات المعيارية المحولة

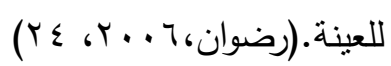

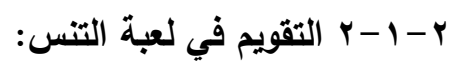
يؤدي التقويم في ضوء الأهداف التربوية الموضوعية والمحددة سابقاً ومحتوى الوحدة التعليمية والهدف الأساسي للتقويم في التتس هو تيسير عملية التعلم لكل فرد وكذا نقدير المتعلمين إذا كان ذلك مطلوباً ويمكن تحديد أهداف التقويم بدقة أكثر في:

قياس مدى تحصيل المتعلمين، تصنيف الطلاب، قياس مدى التحسن، نتخيص صعوبات التعلم لدى الطلاب

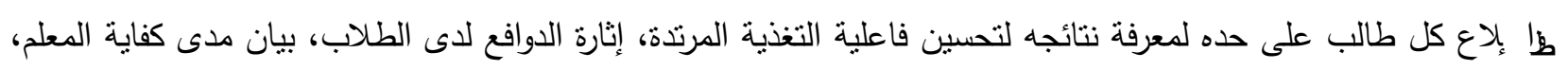

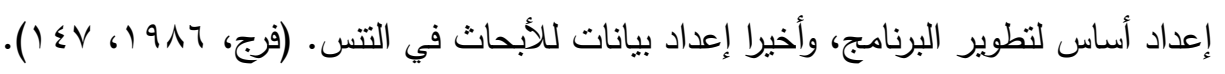

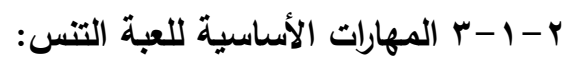
إن لعبة التتس كأي لعبة أخرى لها مبادئها الأساسية التي تشكل الدعامة القوية التي نستتد عليها وان تقويم مسنوى

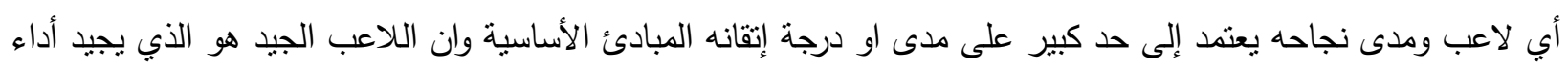

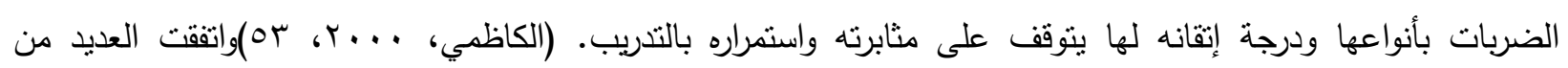

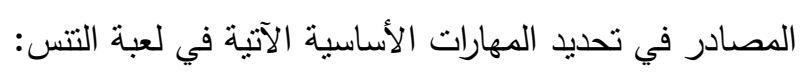

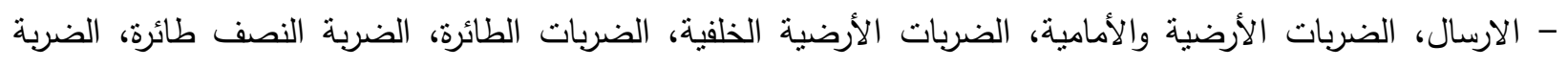

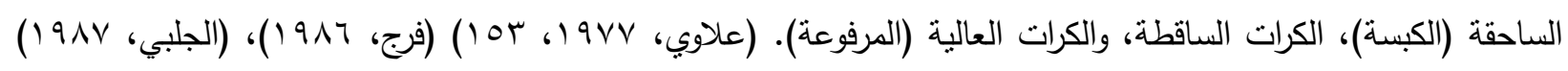

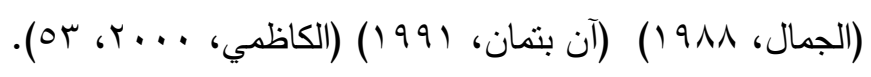




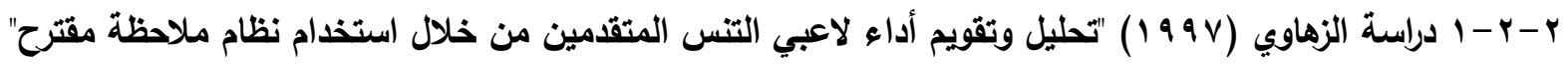

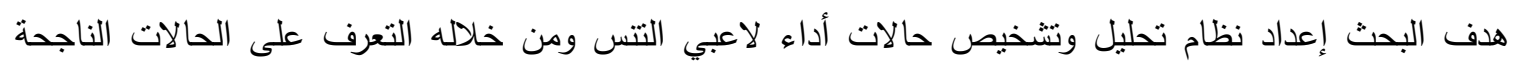
والفاشلة للمهارات وبعدها تقويم لأداء اللاعبين المتقدمين للتنس في العراق وقد استخدم الباحث المنهج الوصفي وأسلوب تحليل ثمانية مباريات كاملة وقد اقترح نظام ملاحظة من خلال التصوير الفديوي وشملت عينة البحث (^) لاعبين متقدمين وكان من

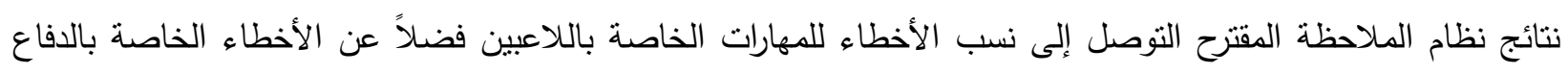
وأخطاء اللعب قرب الشبكة وأوصى عدة نوصيات بناء على نتائج التحليل.

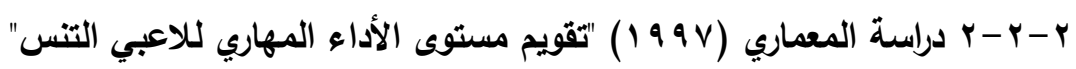

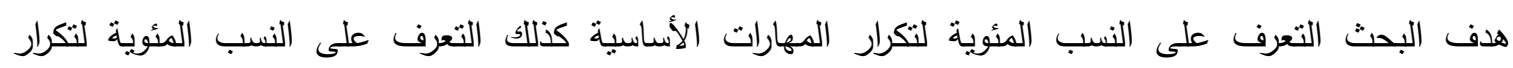
المهارات الناجحة والفاشلة للاعبي التتس. وقد استخدم الباحث المنهج الوصفي بأسلوب الملاحظة العلمية الدقيقة وكان مجتمع البحث لاعبو التتس المشاركين

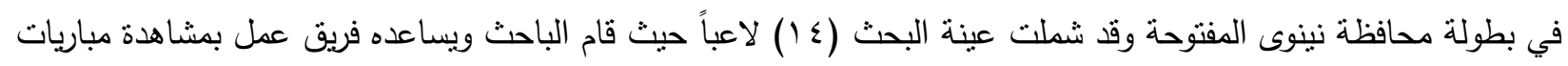
التتس الخاصة بالبطولة وخصر وتسجيل كل المهارات التي تحدث الناجحة والفاشلة اذ نم تحليل (1 (1) لعبة وتم استخدام

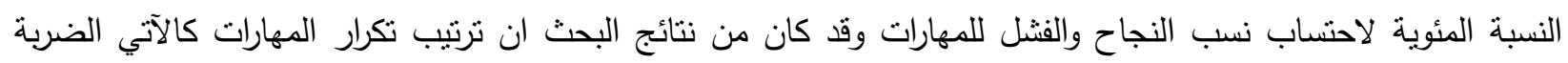

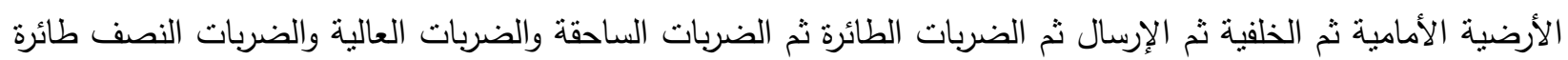

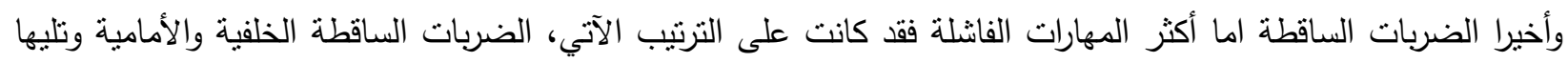
الضربات نصف الطائرة الخلفية والأمامية ثم الإرسال تليها الضربات الطائرة الخلفية والأمامية. وأوصى الباحث باعتماد النسب في المناهج التدريبية والتعليمية والارتقاء بمستوى المهارات الفاثلة وتطويرها.

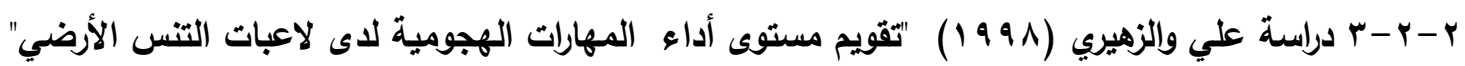

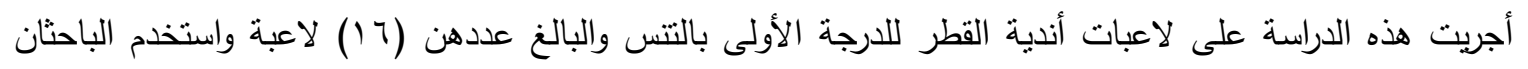
استمارة الملاحظة العلمية وتسجيل البيانات وقد استتتجا أن أعلى نسب محاولات للمهارات الهجومية حصلت عليه مهارة

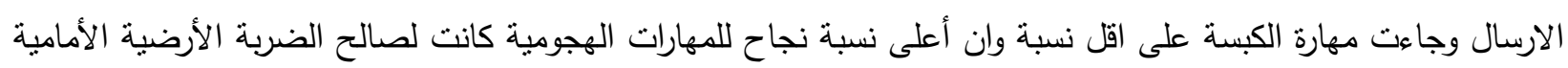
والخلفية وكان أعلى نسبة فثل للضربة الأرضية الخلفية المستقيمة يليها الكبسة.

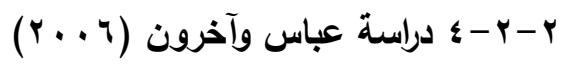
"تحديد مستويات معيارية لبعض الاختبارات البذنية والمهارية في التنس الأرضي لطلبة السنة الثالثة بكلية التربية البذنية بالزاوية" هدف الدراسة اختبار وتقتين مجموعة من الاختبارات البدنية والمهارية وتحديد مستويات معيارية لعينة البحث وقد

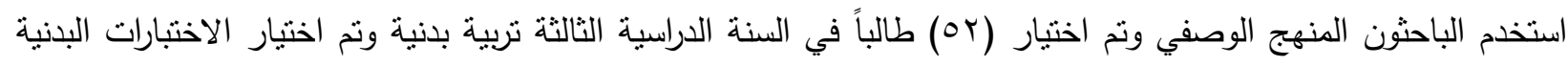
والمهارية وتطبيق الاختبارات ومعالجتها احصائياً ثم النوصل إلى جداول الدرجات المعيارية للاختبارات البدنية والمهارية وكانت

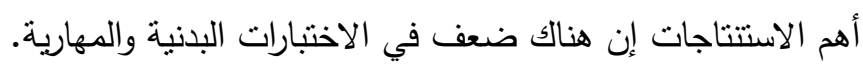
r- r إجراءات البحث: r- امنهج البحث: تم استخدام المنهج الوصفي لملائكته لطبيعة البحث وأهدافه.

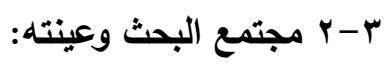

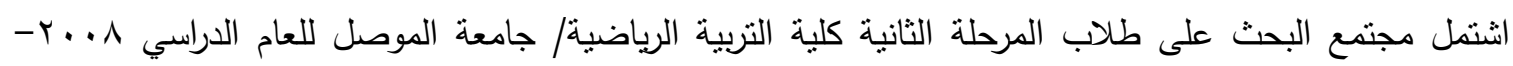

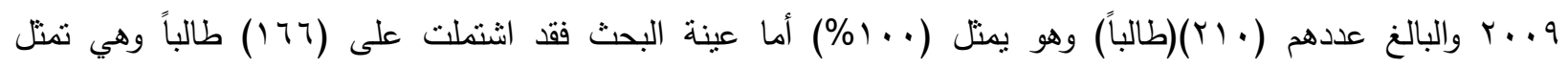

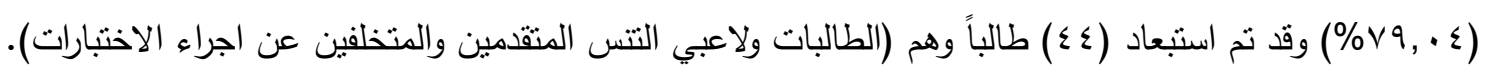


r-r وسائل جمع البيانات:استخدم الباحثان الاختبارات كوسائل لجمع البيانات حيث الباتية نم اختيار (ثلاثة) اختبارات لقياس

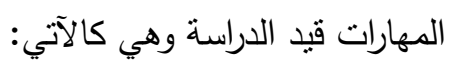
ا-اختبار هوايت للتحصيل في التتس: لقياس مهارتي الضربة الأرضية الأمامية، الضربة الأرضية الخلفية. حيث

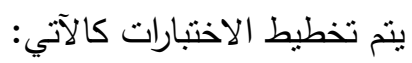
اذ يقوم المدرب برمي الكرة إلى المختبر الذي يعيدها بضربة أرضية أمامية (• (1) محاولات ثم بضربة أرضية خلفية

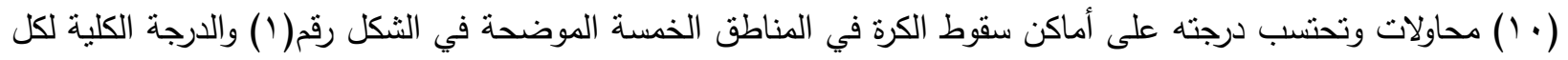

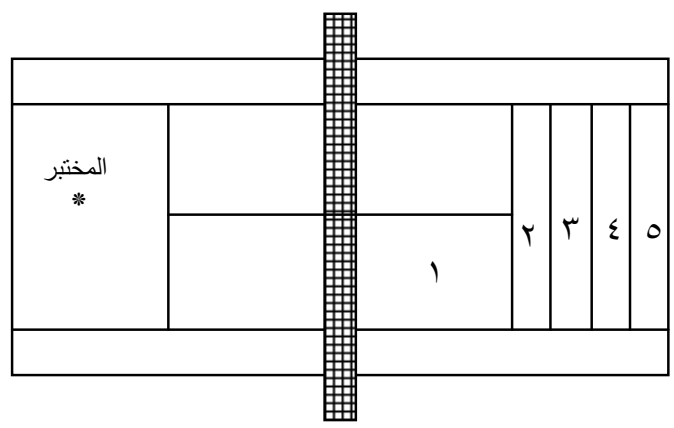

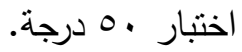

المخطط رقم(1) يوضح اختبار الضريتين الأمامية والخلقية (مجيد، 9199، 1949)

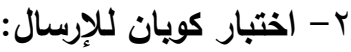

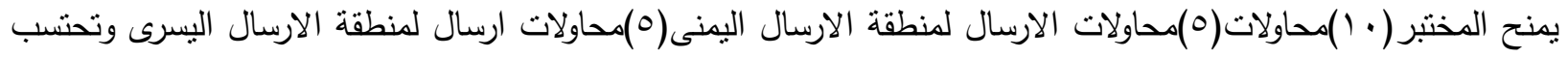

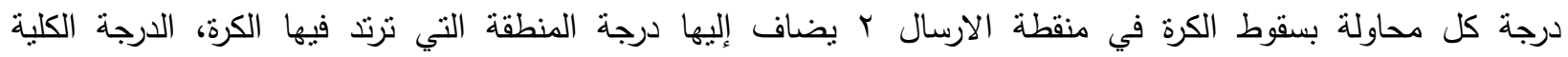

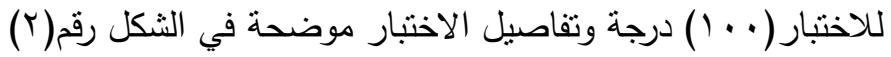

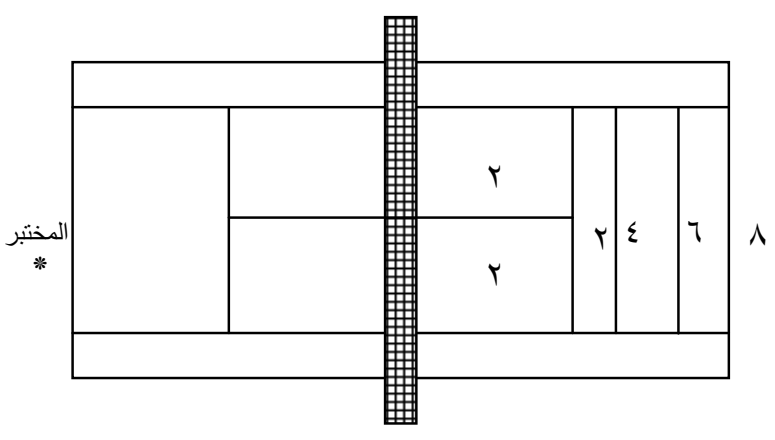

المخطط رقم(ץ) يوضح اختبارا لإرسال لكويان (فرج، 9919 19، 190)

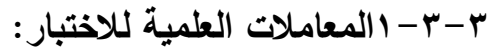

تتتنع الاختبارات المستخدمة في هذه الدراسة بالثروط العلمية للاختبار حيث تم استخدامها في الكثير من الدراسات ومنها

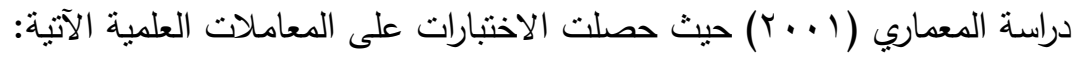

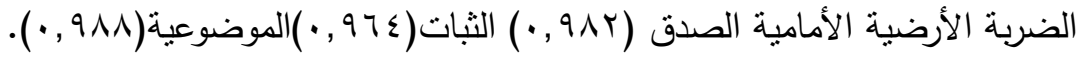

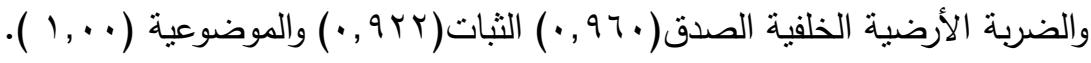
أما اختبار كوبان للإرسال فقد كانت معاملاته العلمية كالآتي:

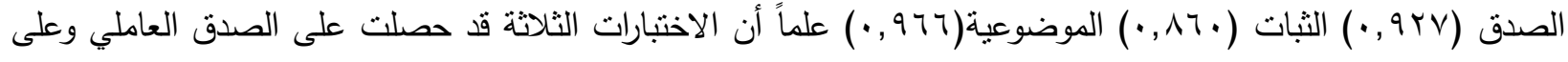

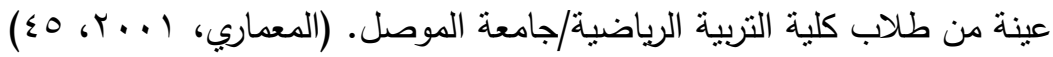


تم تطبيق الاختبارات النهائية على عينة البحث والتي استغرقت أسبوعين وقد راعى الباحثان النقاط الآثية:

- - مإجراء إحماء موحد للعينة عند تطبيق الاختبارات.

- - شرح طريقة أداء الاختبار وكيفية احتساب الدرجة الكلية للمختبر •

- - إعطاء محاولات تجريبية للمختبرين.

وقد تم إجراء اختبار هوايت للضربة الأرضية الأمامية والخلفية كل على حدا في الأسبوع الأول ثم اختبار (كوبان) للإرسال في الأسبوع الثاني.

ب-ه - الوسائل الإحصائية:

تم استخدام الحاسوب الآلي باستخدام برنامج(spss) للوصول إلى المعالجات الإحصائية الآتية:

- - وسط حسابي، انحراف معياري، معامل الالتواء، النسبة المئوية.

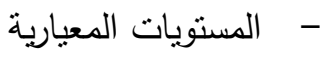

צ - عرض النتائج ومناقشتها:

الجدول رقم (1) الوسط الحسابي والانحراف المعياري والتوزيع الطبيعي للاختبارات المهارية لعينة البحث.

\begin{tabular}{|c|c|c|c|c|}
\hline معامل الالتواء & الانحراف المعياري & الوسط الحسابي & الارجة الكلية للاختبار & الاختبارات \\
\hline •,rMl & $\varepsilon, \vee \neg r$ & rV,rro & 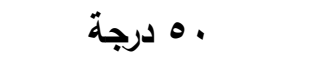 & الضربة الأرضية الأمامية \\
\hline$\cdot, r Y V$ & $v, 1+q$ & $r_{0, r_{0}}$ & • درجة & الضرية الأرضية الخلفية \\
\hline$-\cdot, r \vee \varepsilon$ & Ir,ory & $\varepsilon \wedge, r q$ & . . 1 درجة & ضربة الارسال \\
\hline$-, \mu, r$ & I^, & $110, r r$ & . . . ب درجة & الارجة الكلية للاختبارات \\
\hline
\end{tabular}

من الجدول رقم ( ) يتبين لنا أن عينة البحث:

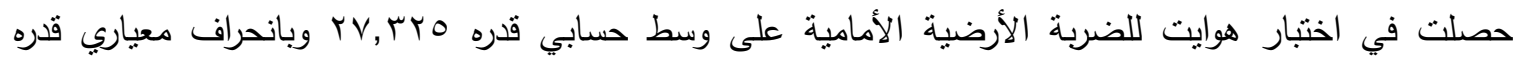

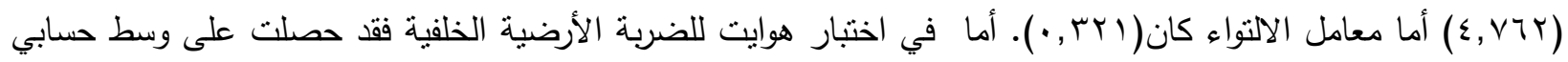

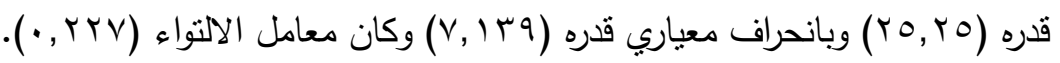

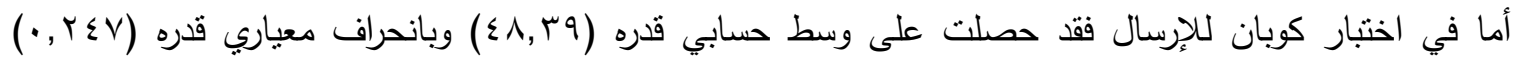

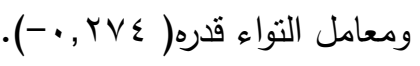

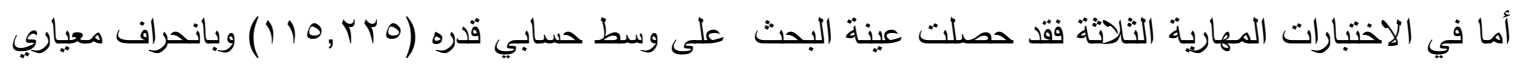

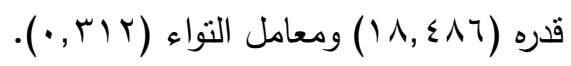

ومن خلال هذه المعالجات الإحصائية تتضح أن أداء أفراد عينة البحث يقع في حدود الأداء المنوسط إذ يظهر ذلك إهاء

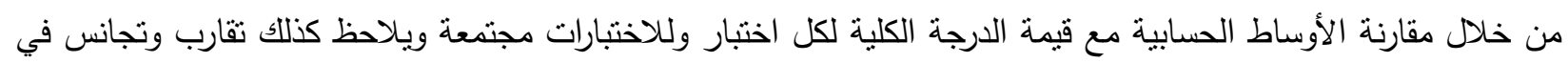
الأداء على الاختبارات إذ إن قيم الانحرافات المعيارية منخفضة وان جميع قيم الأوساط الحسابية قد جاوزت قيم الانحرافات المعيارية وهذا يعد احد مؤشرات انتظام العينة.

ويتنين من الجدول ذاته ان جميع قيم معامل الالنواء كانت واقعة ما بين (1) (1) مما يؤكد تحقيق ملائمة ومناسبة

الاختبارات من حيث سهولتها وصعوبتها لعينة البحث.

وللوصول على مستويات عينة البحث في الاختبارات المهارية الثناثة فقد لجأ الباحثان إلى تقسيمات منحنى كاوس

للتوزيعات الطبيعية "حيث يقوم هذا التقسيم على افتراض ان السمات والصفات والقدرات المختلفة تتوزع بين مجموع الأفراد بشكل اعتدالي وغالباً ما يظهر هذا المنحنى على شكل جرس ومن الجدير بالذكر ان الحصول على منحنى التوزيع ألاعتدالي

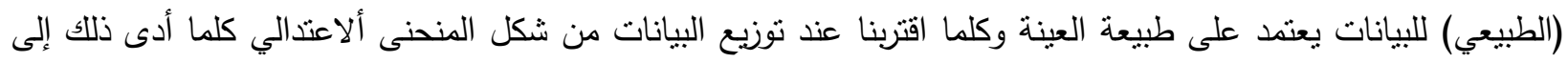

Y). 


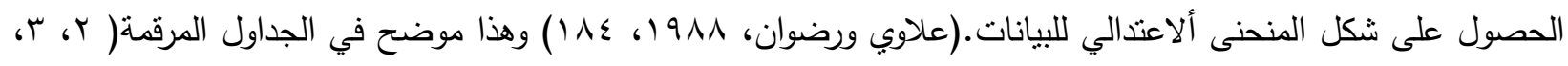

الجدول رقم (ץ) المستويات المعيارية للضربة الأرضية الأمامية لعينة البحث".

\begin{tabular}{|c|c|c|c|}
\hline النسبة المئوية & 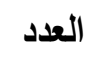 & المستويات & الارجات الخام \\
\hline ז & 11 & ضعيف جداً & ي, Vا فما دون \\
\hline $1 \cdot, \wedge \leq$ & 11 & ضعيف & $r r, 0 T r-1 V, \Lambda .1$ \\
\hline$r \cdot, i r$ & 0 . & مقبول & YV,rY $\{-Y Y, O Y r$ \\
\hline$r \leqslant, 11$ & $\varepsilon$. & متوسط & $r r, . \wedge r-r v, r r_{0}$ \\
\hline $17, Y V$ & $r v$ & جيد & $r \checkmark, \wedge \leqslant \wedge-r r, \cdot \wedge \vee$ \\
\hline $1 Y, 00$ & $r$. & جيد جداً & 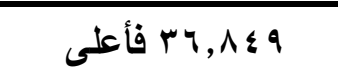 \\
\hline$\% 1 \ldots$ & 179 & & المجموع والنسبة المئوية \\
\hline
\end{tabular}

من النظر في الجدول (Y) يتبين لنا ألآتي:

توزعت عينة البحث على المستويات المعيارية للضربة الأرضية الأمامية بنسب وأعداد مختلفة ولكن يمكن ملاحظة

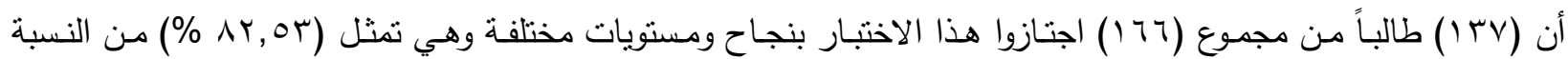

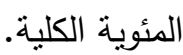

الجدول رقم (ץ) المستويات المعيارية للضربة الأرضية الخلفية لعينة البحث

\begin{tabular}{|c|c|c|c|}
\hline النسبة المئوية & العدد & المستويات & الارجات الخام \\
\hline$\varepsilon, Y r$ & v & ضعيف جداً & ו 19, • ا فما دون \\
\hline 41,79 & rq & ضعيف & $1 \wedge, 11 \cdot-1 \cdot, q \vee r$ \\
\hline צ & IV & مقبول & $r 0, r \leqslant 9-11,111$ \\
\hline$I V, \leqslant V$ & rq & متوسط & $r Y, r \wedge \wedge-r_{\theta, Y}$. \\
\hline $11, \varepsilon$ & 19 & جيا & $r q, \circ r v-r r, r \wedge q$ \\
\hline$\varepsilon$ & $\wedge$ & جيد جداً & 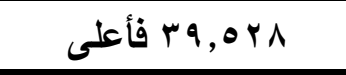 \\
\hline$\% 1 \ldots$ & 174 & & المجموع والنسبة المئوية \\
\hline
\end{tabular}

ومن النظر في الجدول (r) يتبين لنا الآتي:

توزعت عينة البحث على المستويات المعيارية للضربة الأرضية الخلفية بنسب وأعداد مختلفة ولكن يمكن ملاحظة أن

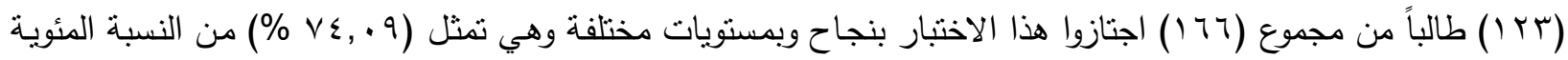


الجدول رقم (؛ ) المستويات المعيارية لضرية الارسال لعينة البحث

\begin{tabular}{|c|c|c|c|}
\hline النسبة المئوية & 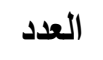 & المستويات & الدرجات الخام \\
\hline$Y, \cdot r$ & 1. & ضعيف جداً & Vاس, اب فما دون \\
\hline $10, .7$ & ro & ضعيف & r \\
\hline$r \wedge, r l$ & $\varepsilon \wedge$ & مقبول & $\varepsilon \wedge, r \wedge q-r \leq, \wedge \diamond \leqslant$ \\
\hline$r r, 0$. & rq & متوبط & $\neg, q \vee \nabla-\varepsilon \wedge, r q$ \\
\hline$r \cdot, \leqslant \Lambda$ & ع & جيد & Vo, $\{71-71,947$ \\
\hline 4.74 & 11 & جيد جداً & 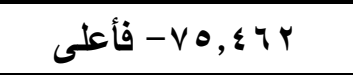 \\
\hline$\% 1 \ldots$ & 179 & & المجموع والنسبة المئوية \\
\hline
\end{tabular}

$$
\text { من النظر في الجدول (ع) يتضح لنا الآتي: }
$$

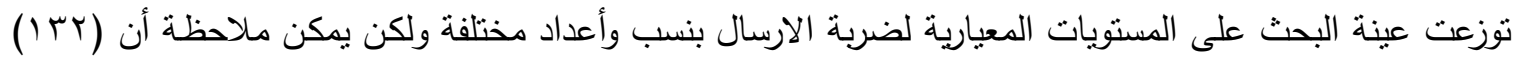

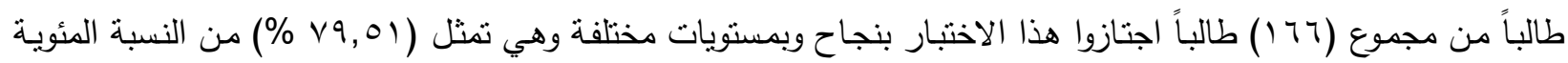

الجدول رقم (•) المستويات المعيارية للمجموع الكلي للمهارات لعينة البحث

\begin{tabular}{|c|c|c|c|}
\hline النسبة المئوية & العدد العد & المستويات & الارجات الخام \\
\hline$\varepsilon, \wedge r$ & $\wedge$. & ضعيف جداً & 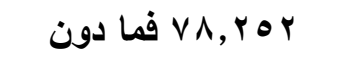 \\
\hline $1 \Lambda, T V$ & $r_{1}$ & ضعيف & $৭ ৭, \vee r \wedge-r \wedge, r \diamond r$ \\
\hline ro, & 09 & مقبول & $110, r r \leq-q \neg, V r q$ \\
\hline$r r, 0$. & rq & متوسط & $1 r r, v \|-110, r r 0$ \\
\hline $1 T, \wedge 7$ & $r r$ & جيد & $10 r, 19 V-|r r, V| r$ \\
\hline$r, \pi$ & 7 & جيا جذاً & 19 19 , 10 - فأعلى \\
\hline$\% 1 \ldots$ & 197 & & المجموع والنسبة المئوية \\
\hline
\end{tabular}

$$
\text { ومن النظر في الجدول (0) يتبين لنا الآتي: }
$$

توزعت عينة البحث على المستويات المعيارية للمجموع الكلي للمهارات بنسب وإعداد مختلفة حيث يمكن ملاحظة أن

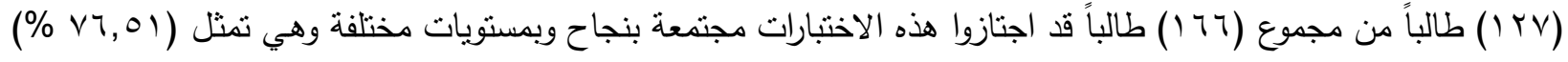
من النسبة المئوية الكلية. وقد يعني نجاح مستوى القدرات المهارية لطلاب السنة الدراسية الثانية في مهارات الضربة الأرضية الأمامية والخلفية وضربة الإرسال.

ومن خلال تحليل الجداول المرقمة (ب ، ؟، ؛ ) يمكن ملاحظة ان الضربة الأرضية الأمامية قد حصلت على نسب نجاح (r,or \% \% من النسبة المئوية الكلية وهذه النتيجة تتفق مع كثير من المصادر في أن تعليم وتدريب الضربة الأرضية الأمامية أسهل وأكثر نجاحاً من بقية المهارات الأخرى.

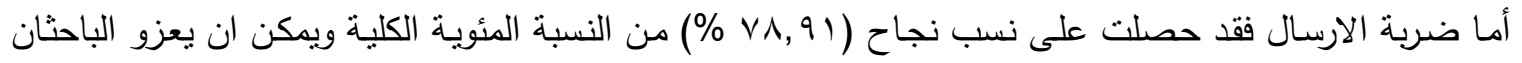
نسبة نجاح هذه المهارة إلى أن للاعب الفترة الكافية للتركيز لنجاح الارسال ويمكن أن يتعزز هذا النجاح بدافعية الاختبار (الامتحان العملي). 


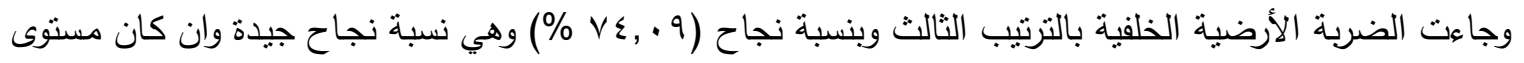

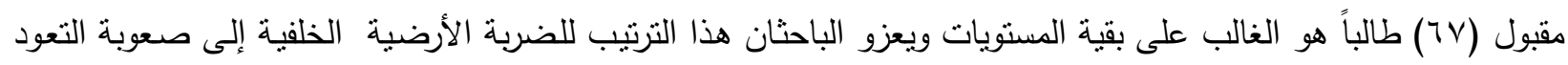

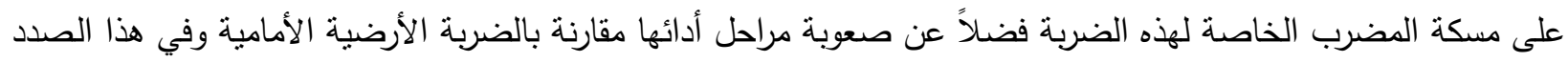

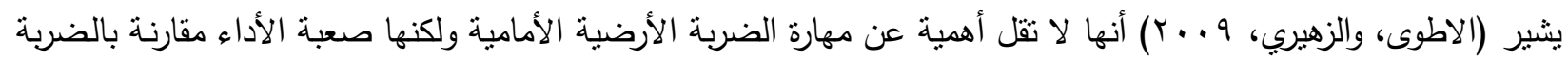

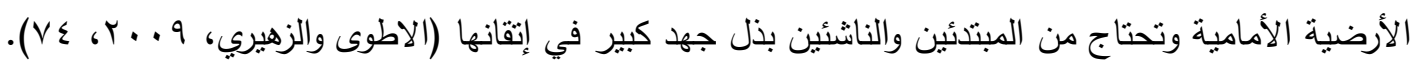

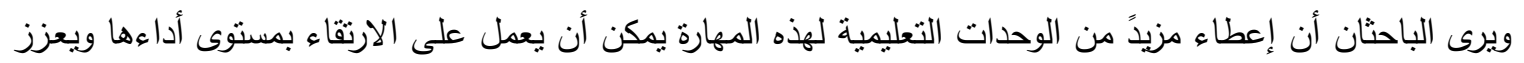

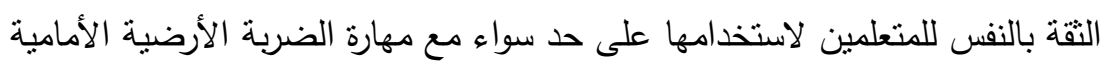
ه- الاستنتاجات والتوصيات: ه- الاستنتاجات:

من خلال ما تم عرضه ومناقتته توصل الباحثان إلى الاستتناجات الآتية:

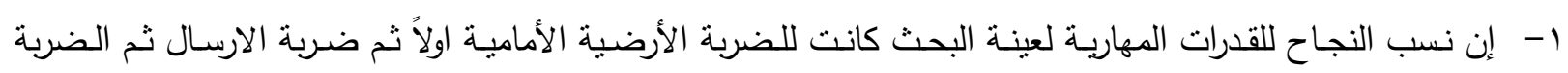
الأرضية الخلفية. ץ- حصول عينة البحث على نسب نجاح وبمستويات مختلفة في القدرات المهاريـة للمهارات كل على حده والمهارات مجتمعة. ب- تـم التوصل إلى جداول المستويات المعياريـة للقدرات المهاريـة لعينـة البحث لكل مهارة على حدا وللمهارات الثلاثة مجتمعة.

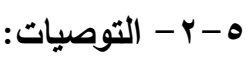
بناء على الاستتناجات يوصي الباحثان: ا - الاعتماد على الاختبارات الموضوعية والتقويم بشكل مستمر في الكثف والتقدير لمستوى القدرة المهارية لعينة البحث لأهميتها في التعرف على مستوى الفرد ولزيادة فاعلية التعلم والتحضير للتطور .

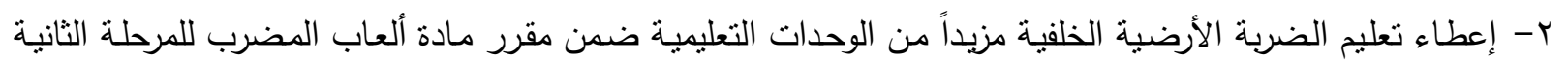
بهدف نطويرها . r- إجراء بحوث أخرى تعتمد في نقويمها على جميع القدرات المهارية المتقدمة الأخرى في لعبة التتس. المصادر العربية: - المراء الاطوى، وليد وعد الله علي والزهيري، سبهان محمود، (9 ـ . ب): العاب كرة المضرب، دار ابن الأثثر للطباعة والنشر، جامعة الموصل.العراق. آن بتمان، (• (99 1)): التتس، ترجمة قاسم لزام، دار الحكمة، بغداد.العراق. الجلبي، طارق حمودي، (9Av (1)، العاب الكرة والمضرب، مديرية دار الكتب للطباعة والنشر ، جامعة الموصل. العراق.

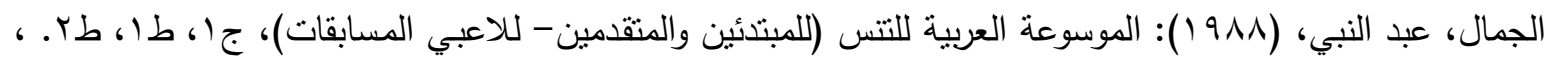
طنطا، مصر .

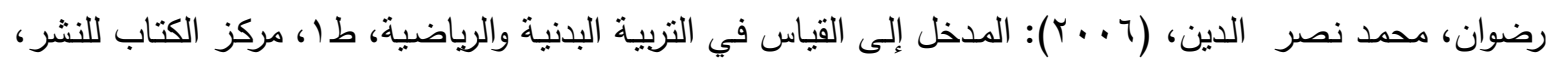
القاهرة.مصر • الزهـاوي، هفال خورشيد، (9VV ( )): تحليل و تقويم أداء لاعبي التنس المتقدمين من خـلال استخدام نظام ملاحظـة مقترح، رسالة ماجسنير غير منشورة، كلية التربية الرياضية، جامعة بغداد.العراق. 


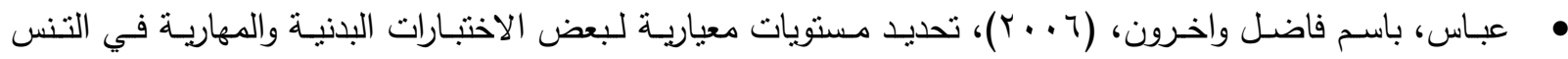
الأرضـي لطلبـة السنة الثالثة بكليـة التربيـة البدنيـة بالزاويـة، بحث منشور في جامعـة السابع من ابريـل، كليـة التربيـة الرياضية، الجماهيرية العربية الليبية. عبد الجبار، قيس ناجي واحمد بسطوسي، (91vV () ): الاختبارات ومبادئ الإحصاء في المجال الرياضي، مطابع التعليم العالي، جامعة بغداد.العراق.

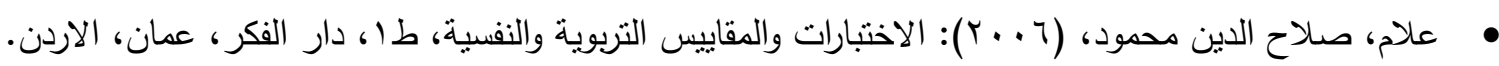

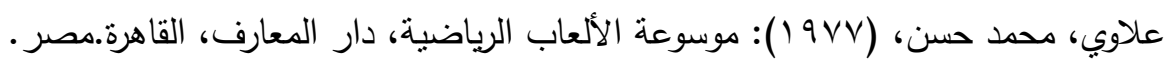

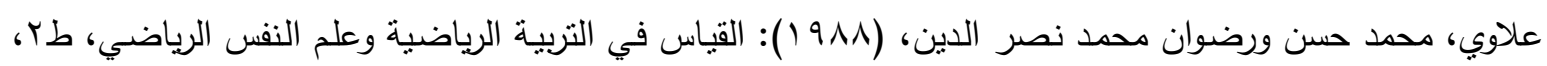
دار الفكر العربي، القاهرة.مصر • ماند علي، وليد وعد الله والزهيري سبهان محمود، (1991) (19): تقويم مستوى أداء المهارات الهجومية للاعبات التنس الأرضي،

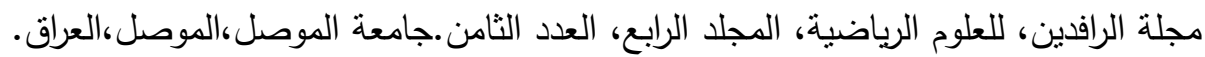

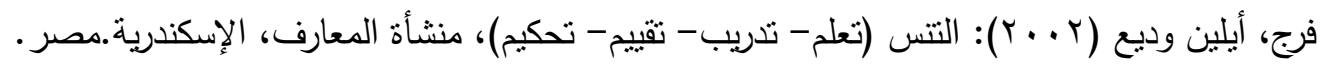

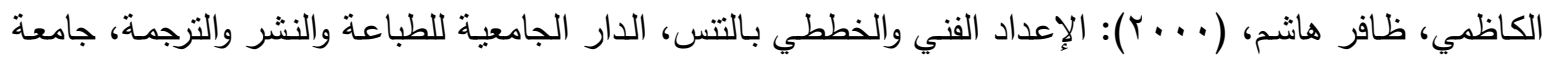

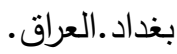
مجيد، ريسان خربيط، (919 (1)): موسوعة القياسـات والاختبـارات في التربيـة البدنيـة والرياضية، جr، مطابع التعليم العالي، جامعة البصرة.العراق. المعماري، إيثار عبد الكريم، (999 (1)): تقويم الأداء المهاري للاعبي التنس، بحث منشور في المؤتمر العلمي الثالث

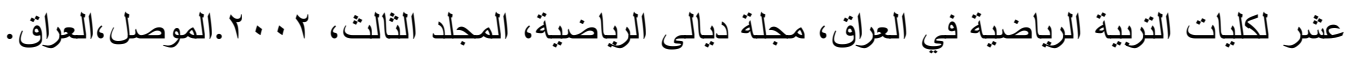

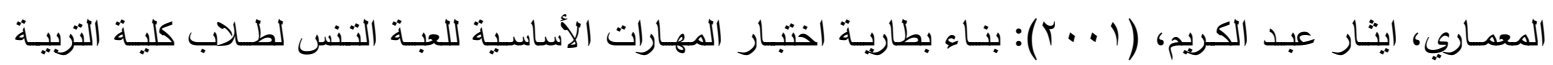
الرياضية، جامعة الموصل، أطروحة دكتوراه غير منشورة، كلية التربية الرياضية، جامعة الموصل.العراق. 